\title{
A RELAÇÃO DA EDUCAÇÃO PROFISSIONAL E TECNOLÓGICA COM A UNIVERSALIZAÇÃO DA EDUCAÇÃO BÁSICA
}

\author{
GaudênCIO Frigotto*
}

\begin{abstract}
RESUMO: Este artigo resulta de uma pesquisa sobre os sujeitos do ensino médio e a relação quantidade e qualidade na educação básica e de debates sobre as políticas de educação básica e técnico-profissional nas últimas três décadas. A reiteração das determinações estruturais da sociedade brasileira, afirmando um projeto de capitalismo dependente, permite entender o elevado grau de analfabetismo adulto, a não universalização e a baixa qualidade da educação básica e a concepção da formação profissional na perspectiva estrita de adaptação aos objetivos do mercado. Uma educação básica de baixa qualidade redunda numa pífia educação profissional. $\mathrm{O}$ artigo evidencia que persistem os desafios de mudanças estruturais na sociedade e na educação, destacando elementos de uma agenda contra-hegemônica.

Palavras-chave: Projeto societário. Educação básica. Educação profissional.
\end{abstract}

THE RELATION BETWEEN PROFESSIONAL AND TECHNOLOGICAL EDUCATION AND THE UNIVERSALIZATION OF BASIC EDUCATION

ABSTRACT: This paper originates from a research on the partakers of secondary education and the quantity-quality relation in basic education and from debates about the basic education policies and technical-professional education in the last three decades. The reiteration of the structural determinations of the Brazilian society, which affirm a dependant capitalism project, helps understand the high rate of adult illiteracy, the non-universalization and low quality of basic education, and the conception of professional training in the strict perspective of an adaptation to market objectives. Poor ba-

Doutor em Ciências Humanas, professor adjunto da Universidade Estadual do Rio de Janeiro (UERJ) e professor titular associado na Universidade Federal Fluminense (UFF). E-mail: gfrigotto@globo.com

Educ. Soc., Campinas, vol. 28, n. 100 - Especial, p. 1129-1152, out. 2007

Disponível em <http://www.cedes.unicamp.br> 
sic education translates into execrable professional education. This paper shows that the challenges of structural shifts in society and in education persist and highlights relevant elements for a counter-hegemonic agenda.

Key words: Societary project. Basic education. Professional education.

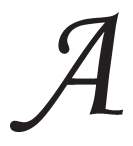

análise que empreendemos neste texto se origina tanto da atividade acadêmico-científica, quanto da inserção no debate das políticas públicas de educação básica e educação profissional técnica e tecnológica. Sob o primeiro aspecto, fundamenta-se num conjunto de trabalhos de pesquisa e estudos que articulam a construção e reconstrução teórica com a pesquisa histórico-empírica das relações entre trabalho, educação básica, técnico-profissional e tecnológica. Em relação ao segundo aspecto, refiro-me aos debates em diferentes espaços ligados aos movimentos sociais e às lutas dos trabalhadores, especialmente os da educação.

Destaco, particularmente, os debates promovidos pela Associação Nacional de Pesquisa e Pós-Graduação em Educação (ANPEd), pelas Conferências Brasileiras de Educação (CBEs), pelo Fórum Nacional em Defesa da Educação Pública, pelo Sindicato Nacional dos Docentes de Ensino Superior (ANDES) e pela Confederação dos Trabalhadores em educação (CNTE). No âmbito do atual governo destaco os debates relativos à revogação do Decreto n. 2.208/97.

Sobre este último aspecto, destacam-se os dois seminários realizados no início do governo Lula - o primeiro sobre ensino médio e o segundo sobre educação técnico-profissional - e a Conferência Nacional sobre Educação Tecnológica e Profissional, precedida de Conferências estaduais, efetivada nos últimos meses do primeiro mandato. $\mathrm{O}$ exame do conteúdo dos debates e o perfil dos participantes mostram que, sobretudo na educação tecnológica e profissional, imbricam-se conflito e antagonismo de concepções e, portanto, de disputa política.

Com efeito, o acompanhamento das Conferências estaduais, preparatórias à nacional, os temas debatidos e a composição dos delegados nos permitem concluir que, por trás de cada conceito de conteúdo ou de organização e financiamento da educação profissional e tecnológica, aninha-se um longo embate histórico de caráter político-ideológico que expressa relaçôes de poder que se reiteram em nosso processo 
histórico. Daí por que as intensas disputas nas Conferências estaduais e depois na Conferência nacional com o Sistema $S$ sobre os termos integrar ou articular, a questão da gestão pública e do financiamento.

O que acabamos de sinalizar nos adverte para um dos equívocos mais freqüentes e recorrentes nas análises da educação no Brasil, em todos os seus níveis e modalidades, que têm sido o de tratá-la em si mesma e não como constituída e constituinte de um projeto dentro de uma sociedade cindida em classes, frações de classes e grupos sociais desiguais.

Neste breve artigo sobre a relação entre a educação profissional e tecnológica e a universalização da educação básica discutirei a natureza do projeto societário da burguesia brasileira, a sua relação com o projeto educacional de educação básica e profissional e os desafios de uma agenda de superação. ${ }^{1}$

A desigualdade como produto e condição do projeto dominante da sociedade brasileira

Para entender a natureza da nossa dívida com a educação básica e a educação profissional e tecnológica, nas suas dimensôes quantitativa e qualitativa e na sua relação, é preciso se dispor a entender o tipo de estrutura social que foi se conformando a partir de um país colônia e escravocrata durante séculos e a hegemonia, na década de 1990, sob os auspícios da doutrina neoliberal, de um projeto de um capitalismo associado e dependente. ${ }^{2}$

Os clássicos do pensamento social, político e econômico brasileiro nos permitem apreender as forças que disputaram os projetos societários e entender o que nos trouxe até aqui e suas determinações. Permitem-nos entender, por outro lado, por que o projeto da classe burguesa brasileira não necessita da universalização da escola básica e reproduz, por diferentes mecanismos, a escola dual e uma educação profissional e tecnológica restrita (que adestra as mãos e aguça os olhos) para formar o "cidadão produtivo" submisso e adaptado às necessidades do capital e do mercado. Por outro lado, permitem também entender por que combatem aqueles que postulam uma escola pública, unitária, universal, gratuita, laica e politécnica.

Com efeito, sob ênfases diferentes, vários autores contemporâneos traçam os (des)caminhos que nos conduziram até o presente. Caio 
Prado Júnior (1966) destaca três problemas que convivem e se reforçam na nossa formação social desigual e que impedem mudanças estruturais. O primeiro é o mimetismo na análise de nossa realidade histórica, que se caracteriza por uma colonização intelectual, hoje das teses dos organismos internacionais e de seus intelectuais e técnicos. Os protagonistas dos projetos econômicos e das propostas de reformas educacionais, a partir da década de 1990, se formaram em universidades estrangeiras ícones do pensamento desses organismos e/ou trabalharam nos mesmos. O segundo problema é o crescente endividamento externo e a forma de efetivá-lo pelo alto pelas frações dominantes da burguesia brasileira. E, por fim, o último constitui-se pela abismal assimetria entre o poder do capital e do trabalho, configurando uma das forças de trabalho de maior nível de exploração do mundo.

Celso Furtado, o autor que mais publicou sobre a formação econômico-social brasileira e a especificidade do nosso desenvolvimento, sintetiza sua visão crítica aos rumos das opções que o Brasil reiteradamente tem pautado dentro do seguinte dilema: a construção de uma sociedade ou de uma nação onde os seres humanos possam produzir dignamente a sua existência, ou a permanência em um projeto de sociedade que aprofunda sua dependência, subordinada aos grandes interesses dos centros hegemônicos do capitalismo mundial. ${ }^{3}$

Dois autores contemporâneos, de modo mais incisivo, nos permitem aprender a especificidade do tipo de sociedade capitalista em que nos constituímos e quais são as nossas (im)possibilidades e desafios. Contrariando não só o pensamento conservador, mas também de grande parte do pensamento da esquerda brasileira, Florestan Fernandes (1975 e 1981) e Francisco de Oliveira (2003) rechaçam a tese dual que atribui nossos impasses para nos desenvolvermos à existência de um país cindido entre o tradicional, o atrasado, o subdesenvolvido e o moderno e desenvolvido, sendo as características primeiras impeditivas do avanço das segundas. Pelo contrário, mostram-nos estes autores a relação dialética entre o arcaico, atrasado, tradicional, subdesenvolvido, e o moderno e o desenvolvido na especificidade ou particularidade de nossa formação social capitalista.

O que se reitera para Fernandes (1981), no plano estrutural, é que as crises entre as frações da classe dominante acabam sendo superadas mediante processos de rearticulação do poder da classe burguesa, numa estratégia de conciliação de interesses entre o denominado arcaico 
e o moderno. Trata-se, para o autor, de um processo que reitera, ao longo de nossa história, a "modernização do arcaico" e não a ruptura de estruturas de profunda desigualdade econômica, social, cultural e educacional.

Na mesma direção de Fernandes (1981) e embasado numa análise que sistematiza há mais de quarenta anos, Oliveira (2003) nos evidencia que é justamente a imbricação do atraso, do tradicional e do arcaico com o moderno e desenvolvido que potencializa a nossa forma específica de sociedade capitalista dependente e de nossa inserção subalterna na divisão internacional do trabalho. Mais incisivamente, os setores denominados de atrasados, improdutivos e informais se constituem em condição essencial para a modernização do núcleo integrado ao capitalismo orgânico mundial.

Dito de outra forma, os setores modernos e integrados da economia capitalista (interna e externa) alimentam-se e crescem apoiados e em simbiose com os setores atrasados. Assim, a persistência da economia de sobrevivência nas cidades, uma ampliação ou inchaço do setor terciário ou da "altíssima informalidade" com alta exploração de mão-de-obra de baixo custo foram funcionais à elevada acumulação capitalista, ao patrimonialismo e à concentração de propriedade e de renda.

Quase quarenta anos depois de publicar Crítica à razão dualista, Oliveira (2003) atualiza a sua análise com o adendo de um novo capítulo, cujo título é "O ornitorrinco". Para o autor, a imagem do ornitorrinco faz a síntese emblemática das mediações do tecido estrutural de nosso subdesenvolvimento e a associação subordinada aos centros hegemônicos do capitalismo e os impasses a que fomos sendo conduzidos no presente.

A metáfora do ornitorrinco nos traz, então, uma particularidade estrutural de nossa formação econômica, social, política e cultural, que nos transforma num monstrengo em que a "exceção" se constitui em regra, como forma de manter o privilégio de minorias. As relações de poder e de classe que foram sendo construídas no Brasil, observa o autor, permitiram apenas parcial e precariamente a vigência do modo de regulação fordista, tanto no plano tecnológico quanto no plano social. Da mesma forma, a atual mudança técnico-científica de natureza digital-molecular, que imprime uma grande velocidade à competição e à obsolescência dos conhecimentos, torna nossa tradição de dependência e cópia ainda mais inútil. 
O monstrengo configura o presente de forma emblemática por uma sociedade que se mantém entre as 15 de maior PIB do mundo e onde um dos setores que mais contribuem para as metas de superávit primário ao redor de 5\%, garantia para os bancos credores, vem do agronegócio e, ao mesmo tempo, estamos um século atrasados na efetivação da reforma agrária e convivendo com 4 milhões de famílias, aproximadamente 20 milhões de pessoas, nos acampamentos dos semterra. Mais elucidativo e cínico é que justamente o programa social de maior impacto do início do governo Luiz Inácio da Silva (Lula) foi o Fome Zero, cujo objetivo tem sido a possibilidade de dezenas de milhôes de pessoas terem as refeições básicas todos os dias.

A transição inconclusa da década de 1980 e a adesão subordinada ao Consenso de Washington a partir do governo Collor, mas realizado sobretudo nos oito anos de governo Fernando H. Cardoso, aprofundaram o fosso de uma sociedade que se ergueu pela desigualdade e se alimenta dela. Define-se, na denominada "era Cardoso", o embate de forças que atravessaram o século Xx e que se explicitam na metáfora do pêndulo utilizada por Ianni (1966) as forças que se alinhavam numa perspectiva de uma sociedade capitalista associada e dependente aos centros hegemônicos do capital-mundo e as que postulavam um desenvolvimento nacional autônomo e com relações sem declinar da soberania. No plano ideológico, nesta segunda alternativa, se encontravam e encontram forças que têm como projeto societário a construção do socialismo. ${ }^{4}$

A questão que se coloca hoje é em que medida os quase cinco anos de governo Luiz Inácio da Silva prosseguiram ou alteraram essa tradição histórica. Um balanço das análises do pensamento crítico de esquerda nos mostra que, no fundamental, não alterou essa tradição e, o que é pior, está desarticulando as lutas do campo da esquerda e os movimentos sociais duramente construídos ao longo do século XX. ${ }^{5}$

Para Pochmann (2004), acentuou-se o empobrecimento e esvaziamento da classe média e ampliou-se a polarização de lados opostos da pirâmide social com a elevação da concentração de renda e de capital e o aumento significativo dos inseridos precariamente na base da pirâmide. Isso resulta, para o autor, da política monetarista e fiscal que, de um lado, dá garantias aos ganhos do capital, mormente o capital financeiro, e, de outro, sustenta programas de renda mínima para os 
grandes contingentes como estratégia de diminuição da indigência e pobreza absolutas. Na mesma direção, Paulani (2006) nos evidencia que se afirma cada dia mais no Brasil a política monetarista e rentista e, como conseqüência, não apenas o agravamento do desemprego estrutural e trabalho precário, mas a oferta de empregos de baixíssimo valor agregado e dominantemente de trabalho simples.

As políticas focais de "alívio à pobreza" lhes garantiram o segundo mandato. Aí reside o "ovo de serpente" se não se proceder a uma mudança estrutural que produza uma inclusão efetivamente de distribuição de renda. Isso demandará um desenvolvimento que gere empregos de valor agregado e uma efetiva universalização da educação básica de qualidade social efetiva e, articulada a esta, a educação profissional e técnica que não se reduza ao adestramento pragmático do mercado. Isso, sem dúvida, implicará abandonar a política econômica monetarista e rentista e encarar as reformas estruturais proteladas por séculos. É nessa encruzilhada que o novo mandato se aninha numa espécie de esfinge: ou decifra-me ou te devoro. ${ }^{6}$

No próximo item, buscaremos analisar as indicações históricas que nos levam a concluir que, para o projeto societário historicamente até aqui dominante, mesmo em termos restritos de uma sociedade capitalista, não há necessidade da universalização da educação básica de efetiva qualidade, mormente o ensino médio e, como conseqüência, a ênfase da formação técnico-profissional e "tecnológica" é de caráter restrito e de alcance limitado.

A universalização ausente e a relação fraca entre a educação básica e a formação técnico-profissional

Que tipo de projeto de educação escolar básica e de formação profissional e tecnológica se coloca como necessário para uma sociedade que moderniza o arcaico e onde o atraso de determinados setores, a hipertrofia do trabalho informal e a precarização do trabalho formal, o analfabetismo etc. não são obstáculos ou impeditivos ao tipo de desenvolvimento que se ergueu pela desigualdade e se alimenta dela?

Diferentes elementos históricos podem sustentar que, definitivamente, a educação escolar básica (fundamental e média), pública, laica, universal, unitária e tecnológica, nunca se colocou como necessidade e 
sim como algo a conter para a classe dominante brasileira. Mais que isso, nunca se colocou, de fato, até mesmo uma escolaridade e formação técnico-profissional para a maioria dos trabalhadores, a fim de prepará-los para o trabalho complexo que é o que agrega valor e efetiva competição intercapitalista.

Um breve retrospecto histórico nos indica uma trajetória de interrupçóes dos projetos societários que postulavam as reformas estruturais e os investimentos em educação, ciência e tecnologia, condições necessárias à constituição efetiva de uma nação soberana, mediante ditaduras e golpes. Os movimentos que configuraram a Semana da Arte Moderna foram abortados ou cooptados dentro de um processo de transformismo, com a aliança conservadora da "Revolução de 1930" e, em seguida, a ditadura Vargas. Como mostra Cândido (1984), por não terem sido uma efetiva revolução, as reformas educacionais subseqüentes não resolveram o problema da educação.

Após a ditadura, do fim da década de 1940 até o golpe civil-militar de 1964, novamente a sociedade brasileira retomou seu projeto de nação e na pauta estavam as reformas estruturais e a universalização do que denominamos hoje de educação básica. A resposta truculenta foi a imposição pela violência física e política de um projeto econômico concentrador e espoliador da classe trabalhadora. Ampliou-se, durante vinte anos, o fosso entre ricos e pobres e se evidenciou, a olho nu, o desenvolvimento do Brasil "gigante com pés de barro", como o caracterizou Florestan Fernandes.

O campo da educação teve um ciclo de reformas completo para adaptar-se ao projeto do golpe civil-militar. Sob a égide do economicismo e do pragmatismo, adotou-se a ideologia do capital humano, reiterando nossa vocação de cópia e mimetismo. A Pedagogia do Oprimido, ícone de uma concepção de educação emancipadora de jovens e adultos, foi substituída pelo Movimento de Alfabetização de Adultos (MOBRAL) sob a pedagogia do mercado. A profissionalização compulsória do ensino médio e a formação técnico-profissional, por outro lado, efetivou-se dentro da perspectiva de adestrar para o mercado. A pedagogia do Sistema $S$, em especial do SENAI, como pedagogia do capital, foi incorporada como política dos governos militares para o campo da educação.

A ditadura é indicador de falta de hegemonia. Vale dizer, é a imposição pela força de um determinado projeto e, por isso, as disputas 
são anuladas, mas cerceadas. Após 20 anos de ditadura, novamente o Brasil, muito embora num contexto histórico marcado já pela ideologia neoliberal e da globalização, inicia uma longa transição para a democratização da sociedade. O processo constituinte afirma a democracia política com a promulgação da Constituição de 1988. Nele, de forma contraditória e ambígua, estão proclamados os horizontes para avançar na democracia social. Todavia, as forças conservadoras, uma vez mais, abandonam a constituição e a submetem, por decretos, medidas provisórias e artifícios jurídicos, a uma letra morta.

Com o governo Collor, inicia-se a cega adesão à doutrina neoliberal. O debate político e econômico são substituídos pelo discurso técnicogerencial e pelo ideário do ajuste, descentralização, flexibilização e privatização. Este ideário foi tornado conseqüência prática nos oito anos do governo Fernando H. Cardoso, de forma competente, segundo os ditames do que foi conhecido como o Consenso de Washington ou a cartilha do ajuste dos países dependentes para se adequarem aos objetivos dos centros hegemônicos do sistema capitalista mundial.

O campo educacional, como assinalamos na abertura deste texto, ganha compreensão no embate de forças mais amplo que se dá no âmbito político e econômico. A longa experiência e detalhadas análises levaram Florestan Fernandes (1992) a preconizar o que iria ocorrer com a educação após a promulgação da Constituição de 1988. Para ele, a educação nunca foi algo de fundamental no Brasil, e muitos esperavam que isso mudasse com a convocação da Assembléia Nacional Constituinte. Todavia, a Constituição promulgada em 1988, confirmando que a educação é tida como assunto menor, não alterou a situação.

A aprovação final dos textos da Lei de Diretrizes e Bases e do Plano Nacional de Educação, em ambos os casos derrotando as forças vinculadas a um projeto nacional popular, veio confirmar as conclusões acima assinaladas de Antônio Candido e Florestan Fernandes em relação aos últimos setenta anos no campo educacional.

Do ciclo de reformas educativas do golpe civil-militar centrado na ideologia do capital humano, transitamos para um ciclo de reformas sob a ditadura do capital. A travessia efetivou-se, perversamente, pela profunda regressão das relaçóes sociais e com um aprofundamento da mercantilização da educação no seu plano institucional e no seu plano pedagógico (Frigotto, 2002). No âmbito do pensamento pedagógico, o 
discurso em defesa da educação é dominantemente retórico ou colocado de forma inversa tanto na ideologia do capital humano (conjuntura da década de 1960 a 1980), quanto nas teses, igualmente ideológicas, da sociedade do conhecimento, da pedagogia das competências (Ramos, 2001) e da empregabilidade (décadas de 1980 e 1990).

No primeiro caso, a noção de capital humano mantinha, no horizonte da classe dominante, a idéia da educação como forma de integração, ascensão e mobilidade social. No segundo caso, com a crescente incorporação de capital morto com a ciência e tecnologia, como forças produtivas diretas, e a ampliação do desemprego estrutural e de um contingente de trabalhadores supérfluos, as noçōes de sociedade do conhecimento, qualidade total, cidadão produtivo, competências e empregabilidade indicam que não há lugar para todos e o direito social e coletivo se reduz ao direito individual.

Essas noçōes, todavia, têm um poder ideológico letal e apresentam a realidade de forma duplamente invertida: o nosso desenvolvimento está barrado porque temos baixos níveis de escolaridade e os trabalhadores não têm emprego porque não investiram em sua empregabilidade, isto é, o quantum de educação básica e de formação técnico-profissional que os constitua reconhecidos e desejáveis pelo mercado como "cidadãos produtivos" (Frigotto \& Ciavatta, 2006).

O que se oculta é opção da classe dominante brasileira de sua inserção consentida e subordinada ao grande capital e nosso papel subalterno na divisão internacional do trabalho, com a hipertrofia da formação para o trabalho simples e as relações de classe nos planos mundial e interno. Ou seja, a sociedade que se produz na desigualdade e se alimenta dela não só não precisa da efetiva universalização da educação básica, como a mantém diferenciada e dual. Assim é que as políticas educacionais, sob o ideário neoliberal da década de 1990 e sob um avanço quantitativo no ensino fundamental e uma mudança discursiva aparentemente progressista no ensino médio e na "educação profissional e tecnológica", aprofundam a segmentação, o dualismo e perpetuam uma relação débil entre ambas.

A quase universalização do ensino fundamental se efetiva dentro de uma profunda desigualdade intra e entre regiōes e na relação cidade/campo. A diferenciação e a dualidade dão-se aqui pelo não acesso efetivo e democrático ao conhecimento. A escola pública dos pobres e/ou 
dos filhos dos trabalhadores, como demonstra histórica e empiricamente a tese de Algebasile (2004), é uma escola que "cresce para menos".

É no ensino médio, definido na Constituição de 1988 e na nova Lei de Diretrizes e Bases de 1996, que podemos melhor perceber o quanto a sua universalização e democratização são desnecessárias ao projeto de sociedade até o presente dominante. O Decreto n. 2.208/97 restabeleceu o dualismo entre educação geral e específica, humanista e técnica, destroçando, de forma autoritária, o pouco ensino médio integrado existente, mormente da rede CEFET. Inviabilizou-se, justamente e não por acaso, os espaços, como sinaliza Saviani (2003), onde existiam as bases materiais de desenvolvimento da educação politécnica ou tecnológica. Ou seja, aquela que oferece os fundamentos científicos gerais de todos os processos de produção e das diferentes dimensões da vida humana.

Mesmo sob essas condições de dualidade, o ensino médio se constitui numa ausência socialmente construída, na sua quantidade e qualidade e como o indicador mais claro da opção da formação para o trabalho simples e da não preocupação com as bases da ampliação da produção científica, técnica e tecnológica e o direito de cidadania efetiva em nosso país.

Apenas cerca de $46 \%$ dos jovens têm acesso ao ensino médio, sendo que mais da metade destes o fazem no turno noturno e, grande parte, na modalidade de supletivo. Quando analisamos por região, a desigualdade aumenta. No campo, por exemplo, apenas $12 \%$ freqüentam o ensino médio na idade/série correspondente, também com enormes desigualdades regionais.

Recente relatório sobre Ensino Médio no campo mostra a ausência quase total de escolas de ensino médio nas áreas de Reforma Agrária que ofertam o ensino médio, sendo mais da metade delas extensões de escolas da cidade. Com efeito, a Pesquisa Nacional da Educação na Reforma Agrária (PNERA, 2004), feita pelo INEP em parceria com o Instituto Nacional de Colonização e Reforma Agrária (INCRA), apontou que entre as 8.679 escolas existentes em assentamentos, apenas 373 delas oferecem o ensino médio. ${ }^{8}$

O alarmante é que não só o INEP avalia que há um déficit de 250 mil professores para o ensino médio como dados recentes revelam que 
em 48\% dos municípios brasileiros o número de matriculados no ensino médio diminuiu. O Censo Escolar de 2006 indica, por outro lado, que houve uma diminuição de 94 mil matriculas no ensino médio regular, em relação a 2005 , e um aumento de 114 mil no mesmo nível na educação de jovens e adultos (antigo ensino supletivo). A hipótese é de que a grande parte desses 94 mil tenha migrado para o nível médio supletivo. ${ }^{9}$

No âmbito da educação profissional e tecnológica, o governo, na década de 1990, valeu-se, como mostra Lobo Neto (2006), do discurso da tecnologia e da "tecnologia" do discurso para organizar um sistema paralelo e dissimular sua efetiva natureza tecnicista. $\mathrm{Na}$ verdade, como nos mostra esse autor, a nomenclatura de "educação profissional" esconde seu contrário - uma política de formação profissional estreita e desvinculada de uma concepção de educação "omnilateral do ser humano historicamente situado" (Lobo Neto, 2006, p. 170). O Decreto n. 2.208/97 também induziu a maioria dos Centros Federais de Educação Tecnológica (CEFETs) a um direcionamento que reduziu o tecnológico a um upgrade da formação técnico-profissional. Um caminho inverso, portanto, ao sentido mesmo de educação tecnológica enquanto base ou fundamento científico das diferentes técnicas e de formação humana nos campos social, político e cultural.

Num outro patamar, criou-se o Plano Nacional de Qualificação do Trabalhador (Planfor), ${ }^{10}$ cujo fundo é disputado pelo Sistema S, ONGs, sindicatos e escritórios de organização de cursos, cujo escopo é a condenação de milhares de jovens e adultos trabalhadores, com escolaridade média de quatro anos, a cursos profissionalizantes, na sua maioria, desprovidos de uma base científica, técnica e de cultura humana mais geral. Isso faz com que não estejam preparados nem para as exigências profissionais, nem para o exercício autônomo da cidadania.

Cabe registrar que o Sistema S, que na década de 1980 se viu pressionado pela sociedade a repensar a sua função social, na década de 1990 não só abandonou essa agenda, mas começou a denominar, especialmente o SENAI, vários de seus departamentos regionais, de unidades de negócio.

Todos os indicadores nos conduzem a perceber que o pêndulo não se movimentou na direção das forças que lutam por um projeto nacional popular e democrático de massa e das conseqüentes reformas 
estruturais, o que implicaria um projeto de educação escolar e de formação técnico-profissional dos trabalhadores para o trabalho complexo, condição para uma inserção ampla na forma que assume o processo de produção industrial-moderno, com base científica digital-molecular. $\mathrm{O}$ projeto de um capitalismo associado e dependente não tem necessidade da universalização do ensino médio de qualidade. Dados recentes mostram que dos poucos egressos do ensino médio muitos se negam a assumir empregos de baixíssimo nível e de salários irrisórios. Preferem migrar para países onde os mesmos serviços são remunerados quatro ou cinco vezes mais.

Uma das cobranças imediatas da área de educação, mediada por suas organizações científicas, culturais e sindicais, presente na proposta de governo, era a revogação do Decreto n. 2.208/97, uma espécie de símbolo da desastrada política educacional da era Cardoso. A demora por mais de dois anos para que isso ocorresse é sintomática. Isto somente ocorreu em 2004 com a promulgação do Decreto n. 5.154/ 04 . Na sua gênese, dentro das contradições da travessia, tratava-se de resgatar a perspectiva do ensino médio na perspectiva da educação politécnica ou tecnológica. Concepção refutada e abertamente combatida pelas forças conservadoras do governo FHC. Daí, contrariamente à perspectiva de aligeiramento e profissionalização compulsória da Lei n. 5.692/71 e do dualismo imposto pelo Decreto n. 2.208/97, o ensino médio integrado amplia de três para quatro anos este nível de ensino para permitir ao jovem uma formação que articule ciência, cultura e trabalho. Uma perspectiva, portanto, que supere tanto o academicismo quanto a visão de profissionalização adestradora. Tratava-se de avançar, tendo como parâmetro as condições materiais dos CEFETs, na concepção da educação politécnica ou tecnológica, no sentido trabalhado por Saviani (2003 e 2006).

Esta proposta não avançou, tanto por falta de decisiva vontade política e recursos do governo federal e resistência ativa de grande parte dos governos estaduais, responsáveis pela política de ensino médio, para implementá-la, quanto por uma acomodação das instituições educacionais e da sociedade em geral. ${ }^{11} \mathrm{Na}$ verdade, a não ser a partir de 2006, com a atual gestão da SEMTEC, o governo sequer atuava com uma definição política até mesmo na rede CEFET, diretamente ligada a ele. Mais que isso, o Conselho Nacional de Educação estabeleceu diretrizes que acabam enquadrando, dominantemente, o novo Decreto den- 
tro do espírito da tradição estreita da formação técnico-profissional, anulando, em grande parte, a revogação do Decreto n. 2.208/97.

Em relação às políticas de qualificação (PLANFOR), o mesmo foi transformado em Plano Nacional de Qualificação (PNQ), com direcionamento mais incisivo na política de emprego e renda mínima para desempregados, subempregados e força de trabalho supérflua. Paralelamente, situam-se também programas de primeiro emprego para jovens trabalhadores que buscam colocação no mercado de trabalho e não conseguem. No Brasil os dados das pesquisas de Pochmann (1998 e 1999) indicam um desemprego de inserção de $42,3 \%$ dos jovens. Nesta perspectiva, ultimamente ganharam grande ênfase política no governo Lula o PROJOvem, a controvertida Escola de Fábrica e o PROEJA. Em relação ao Sistema $S$, não houve mudança significativa, a não ser de induzi-lo a disputar fundos para atuar nos programas citados e na perspectiva dos programas de renda mínima para os grandes contingentes de jovens e adultos, como estratégia de diminuição da indigência e pobreza absolutas.

O balanço no campo da educação do atual governo, pelas opçóes no plano econômico, social e político e pelo abandono das bases sociais organizadas, reitera tanto a precariedade de recursos quanto a permanência do dualismo entre educação geral e específica, humanista e técnica e, portanto, a frágil relação entre educação básica e formação técnico-profissional. Como mostra Oliveira (2006), a mudança deste quadro, na sociedade e na educação, só ocorrerá mediante pressão das forças de esquerda e dos movimentos populares.

Desafios na opção do projeto de sociedade e da relação educação básica e técnico-profissional

A tese básica da necessidade de acelerar o desenvolvimento, apresentada pelo atual governo como plataforma para os próximos quatro anos de debates do segundo turno, precisa ser qualificada no plano teórico e nas definições políticas. A dificuldade desta qualificação e o risco de não sair do mesmo lugar se mostraram nas tensões internas dentro do governo, quando alguns setores explicitaram a convicção de que a era Palocci acabara. Vale dizer, abandonar a política monetarista e rentista, centrada no ajuste fiscal para gerar superávit 
de $4,5 \%$ ou $5 \%$ do PIB, condição sine qua non, é tese do desenvolvimento, é pura retórica.

O sinal preocupante é de que esta tensão foi rapidamente silenciada em nome da unidade de discurso e, certamente, para não "assustar o mercado", os investidores etc. Neste particular, a advertência de Oliveira (2006, p.1) tem, em sua dramática dialeticidade, para além de um posicionamento teórico, um apelo ético-político:

As esquerdas precisam aprender com o pequeno grande sardo Gramsci: a luta política no capitalismo é uma permanente "guerra de posições", e a pregação falsa de unidade acima de tudo somente serve para deixar os flancos abertos para forças contrárias à transformação social. Assim, em certas conjunturas, a palavra de ordem pode ser "dividir para lutar melhor".

A relação de forças certamente não permite rupturas abruptas, mas não se faz omelete sem se quebrar ovos. Ou seja, a mudança de direção certamente vai contrariar interesses de grupos poderosos da burguesia brasileira associada ao grande capital. A questão não é apenas desenvolver de forma sustentável, mas qual o sentido e a quem servem este desenvolvimento e esta sustentabilidade. Nem o termo desenvolvimento nem sustentável definem, por si, a natureza dos mesmos. A história recente do capitalismo mundial e do Brasil tem mostrado que é possível crescer muito - mediante um desenvolvimento desigual e combinado -, aumentando a concentração de renda e capital sem gerar um número significativo de empregos e que os mesmos engendrem efetivo valor agregado para os trabalhadores. Neste contexto, sustentabilidade significa políticas de ajuste fiscal, privatizaçôes, flexibilização e perda de direitos dos trabalhadores.

É neste particular que reside a esfinge que clama por ter seu enigma decifrado ou o salto de qualidade nos próximos anos não se dará. Voltam à tona os quatro aspectos apontados por Perry Anderson para que o governo Lula pudesse, já no primeiro mandato, significar um efetivo avanço na sociedade brasileira e não cair na armadilha da grande maioria dos governos de centro-esquerda e esquerda, que se elegeram após a década de 1980 e que acabaram completando as reformas da direita. Este avanço, para Anderson, implica: não confundir os votos ganhos com o poder; ter um projeto alternativo claro de sociedade e um grupo coeso na busca de sua concretização; vincular este projeto aos movimentos sociais organizados e identificar o inimigo, sem subestimá-lo. ${ }^{12}$ 
A tarefa de decifrar a esfinge não é de pequena monta, pois um projeto de "desenvolvimento sustentável", que se afaste do consenso neoliberal, como sublinha o historiador Hobsbawm (1992, p. 266; grifo meu), "não pode funcionar por meio do mercado, mas operar contra ele". Por isso, para este historiador, a coordenação desse processo não pode ser sustentado nem por ONGs, nem pela Igreja, mas pelo Estado, ainda que não este Estado. Certamente, as parcerias público-privadas que acalentam vários programas do atual governo estão na contramão deste horizonte apontado pelo octogenário historiador.

Esse salto de qualidade tem como exigência encarar frontal e decididamente as reformas estruturais historicamente proteladas: a reforma agrária e a taxação das grandes fortunas, com o intuito de acabar com o latifúndio e a altíssima concentração da propriedade da terra; a reforma tributária, com o objetivo de inverter a lógica regressiva dos impostos, em que os assalariados e os mais pobres pagam mais, corrigindo assim a enorme desigualdade de renda; a reforma social, estatuindo uma esfera pública de garantia dos direitos sociais e subjetivos. Isso pressupóe, também, renegociar as dívidas interna e externa noutros termos.

Este projeto de sociedade e de desenvolvimento demandará um gigantesco investimento em ciência e tecnologia como condição necessária à efetiva universalização democrática da educação básica. Não basta a democratização do acesso, há necessidade de qualificar as condições objetivas de vida das famílias e das pessoas e aparelhar o sistema educacional com infra-estrutura de laboratórios, professores qualificados, com salários dignos, trabalhando numa única escola etc. Para isso, não é suficiente a aprovação do FUNDEB. No contexto do que estamos aqui sinalizando, os fundos se pautam na lógica da "eqüidade mínima" e não na qualidade necessária. Essa implica previsão de recursos constitucionais que, em médio prazo, dilatem por três ou quatro vezes os investimentos atuais em educação básica e superior.

Para o estabelecimento de um vínculo mais orgânico entre a universalização da educação básica e a formação técnico-profissional, implica resgatar a educação básica (fundamental e média) pública, gratuita, laica e universal na sua concepção unitária e politécnica, ou tecnológica. Portanto, uma educação não-dualista, que articule cultura, conhecimento, tecnologia e trabalho como direito de todos e condição da cidadania e democracia efetivas. 
Saviani, sem dúvida, é o educador brasileiro que efetivou a elaboração mais consistente sobre as relaçõoes entre escola básica e mundo do trabalho, na perspectiva da educação politécnica ou tecnológica. Para este autor (2006, p. 14),

(...) se no ensino fundamental a relação é implícita e indireta, no ensino médio a relação entre educação e trabalho, entre o conhecimento e a atividade prática deverá ser tratada de maneira explícita e direta. O saber tem uma autonomia relativa em relação ao processo de trabalho do qual se origina. O papel fundamental da escola de nível médio será, então, o de recuperar essa relação entre o conhecimento e a prática do trabalho.

Como mostra ainda o autor (ibid., p. 15),

(...) esta é uma concepção radicalmente diferente da que propõe um ensino médio profissionalizante, caso em que a profissionalização é entendida como um adestramento em uma determinada habilidade sem o conhecimento dos fundamentos dessa habilidade e, menos ainda, da articulação dessa habilidade com o conjunto do processo produtivo.

A proposta do ensino médio integrado se fundamenta nesta concepção e se constitui, sem dúvida, no grande desafio do atual governo de efetivamente implementá-la. A visão de articulação e não integração da formação profissional à educação básica, defendida pelo Sistema S, representa a perspectiva do dualismo e adestramento.

Há aqui pelo menos dois obstáculos a serem enfrentados pela sociedade e governo. Primeiramente, modificar as diretrizes promulgadas pelo Conselho Federal de Educação que induzem a compreensão do ensino médio a simples arranjos do Decreto n. 2.208/97, na perspectiva da articular e não do integrar e, em última instância, ao retorno do profissionalizante da reforma n. 5.692/71, um adestramento rápido com vistas ao mercado de trabalho. O segundo é quebrar a barreira de resistências das políticas estaduais, sob as quais está a prerrogativa da oferta do ensino médio.

Foram publicados recentemente os resultados do ENEM, os quais nos revelaram aspectos importantes. A imprensa propalou o sucesso das escolas médias públicas federais e de algumas escolas confessionais. O melhor desempenho foi da Escola Politécnica de Saúde Joaquim Venâncio - uma instituição de ensino médio vinculada à Fundação Oswaldo Cruz. Trata-se de uma escola que atende a jovens de camadas populares e de classe média, um público muito diverso do das escolas privadas de elite. 
Por que todas as escolas públicas de ensino médio não têm o mesmo desempenho? Quem responde a essa questão, de forma correta política e cientificamente, é o diretor da Escola Politécnica, professor André Malhão, nas diversas entrevistas que lhe fizeram para que explicasse tal sucesso de desempenho dos alunos. Primeiramente, Malhão adverte que qualquer comparação com as demais escolas da rede pública é inadequada, porque as mesmas estão longe de ter as condições minimante comparativas em termos de professores qualificados (a maioria com mestrado e doutorado), com grupos de pesquisa, laboratórios atualizados, biblioteca, espaço físico. Em segundo lugar, o diferencial está na proposta política e pedagógica da escola, centrada no debate e na concepção da escola unitária e politécnica; uma escola comprometida em formar jovens que articulem ciência, cultura e trabalho e lhes dê possibilidade de serem cidadãos autônomos; que possam escolher seguir seus estudos ou, se têm necessidade, ingressar na vida profissional.

O desafio é de universalizar o ensino médio com esta qualidade teórica, técnica e política. Mas isso significa que a sociedade brasileira terá de ter consciência de que o custo desta educação é, pelo menos, oito a dez vezes maior daquilo que se propóe mediante o FUNDEB. O ensino médio dos países do capitalismo central não custa menos que quatro mil e quinhentos dólares aluno/ano. Isso equivale ao que uma família de classe média das grandes capitais brasileiras paga em escolas particulares laicas ou confessionais.

Pela importância estratégica, também, da rede de Centros Federais de Educação Tecnológica e das redes estaduais e municipais de escolas técnicas de nível médio, é fundamental que as mesmas tenham a possibilidade de restauração plena do nível médio de ensino, na perspectiva da educação politécnica ou tecnológica, e se constituam numa referência efetiva de suas condições físicas, materiais, formação e condições do trabalho docente. Não se trata de negar a prerrogativa do ensino superior, mas de garantir o ensino médio integrado como uma de suas prioridades. Também há que se aprofundar a natureza do ensino superior e das universidades tecnológicas. Aqui se trata de superar o viés que situa a educação tecnológica como upgrade do ensino técnico, numa perspectiva reducionista e estreita.

Um desafio estratégico do governo federal é encontrar formas de uma relação orgânica com a rede de educação profissional e tecnológica dos estados, historicamente secundada e fruto de políticas pouco orgânicas e 
continuadas, por se atrelar ao foco dos governos em exercício e não como uma política pública de Estado.

Outro desfio é o de criar um Sistema ou Subsistema Nacional de Formação/Qualificação Profissional, como política pública, integrado às múltiplas redes existentes e vinculado-as à política de criação de emprego e renda e, no contexto que ainda nos encontramos, à política pública de educação de jovens e adultos.

Cabe, certamente, pensar-se o sistema ou subsistema nacional de formação/qualificação profissional como política pública, estratégica e de Estado, com a tarefa de gerir as várias redes mantidas pelo setor público, nas diferentes esferas, e no setor privado, dentro de uma perspectiva que Melenchon (2003, p. 5) denomina de "resposta a um duplo imperativo do progresso: o acompanhamento da rápida evolução tecnológica e garantia social do trabalhado".

Neste sentido, pela especificidade do sistema $S$, que tem contribuição de fundo público compulsório, o Estado tem a obrigação de discutir uma tendência crescente (com ênfase diversa institucionalmente) de se transformar em empresas de serviços com múltiplas "unidades de negócio". Trata-se de retomar os debates dos anos de 1980, onde se discutia, interna e externamente, a função social deste sistema e a criação dos centros públicos de formação profissional, e de democratizar efetivamente o Sistema $S$.

Os movimentos sociais, as organizações ligadas à classe trabalhadora e o Estado brasileiro devem exercer o controle para que os recursos públicos arrecadados pelo Sistema $S$ tenham um fim claramente público. Por isso, há que se cobrar bem mais que os 30\% de recursos em vagas de alunos do sistema público. É crucial também o debate sobre a natureza da formação profissional dada no Sistema $S$ e sobre quem a define. Os tempos em que vivemos não permitem que a mesma seja efetivada na perspectiva unidimensional de "adestrar as mãos e aguçar o olho", como se referia Gramsci, nos anos de 1930, em relação à educação que interessava ao capital e ao mercado. ${ }^{13}$

Cobrar que o Sistema $S$ volte a oferecer cursos em tempo integral gratuitos parece-nos uma exigência mínima. Há milhões de jovens que necessitam disso nas periferias das pequenas, médias e, sobretudo, grandes cidades e no campo. A ausência de formação profissional nos assentamentos da Reforma Agrária é gritante. O que não é eticamente 
insustentável é transferir esse fundo público para a formação de profissionais, até em nível superior, para multinacionais ou em empreendimentos com a ótica mercantil de unidades de negócio. Neste particular, a questão ética, política e jurídica é a seguinte: se o Sistema $S$ ou parte dele quer ser empresa (unidade de negócio), até para que não haja concorrência desleal no mercado, é preciso que renuncie ao fundo público compulsório, devolva o patrimônio construído ao longo de mais de 50 anos e pague pela marca ou mude de nome. Em outros termos, ou o Sistema $S$ utiliza o fundo público que recebe para políticas públicas orientadas pelo Estado, ou o Estado tem o dever político, social, econômico e ético de rever a legislação que cria o este Sistema.

Em termos mais amplos, cabe postular que a política pública de formação profissional afirme como prerrogativa do Estado, ou a instituiçôes por ele credenciadas, a diplomação e certificação. Ao Ministério da Educação cabe a coordenação do Sistema Nacional de Formação/Qualificação. Também se pressupõe a existência permanente de um fundo garantido na Constituição para esse fim, que inclua, mas vá além do Fundo de Desenvolvimento do Ensino Profissional e de Qualificação do Trabalhador (FUNDEP). Vá além, pois os fundos (FUNDEB e FUNDEP) lidam dominantemente com a questão da eqüidade e não representam acréscimos substantivos do fundo público na educação básica e profissional. Há, por fim, que haver em todas as redes, por um princípio de democracia substantiva, uma gestão com participação efetiva do Estado, dos trabalhadores e do setor produtivo.

Se efetivamente se garante, em médio prazo, a educação básica dentro da concepção da politécnica ou da tecnologia universal, a formação profissional terá uma outra qualidade e significará uma possibilidade de avanço nas forças produtivas e no processo de emancipação da classe trabalhadora. Neste percurso, julgamos importante que a política pública de formação profissional se vincule às políticas de emprego e renda. Isso, por sua vez, implica, como mostramos ao longo deste breve texto, que se politize o debate em todas as esferas, mormente a econômica, rompendo com a doutrina dos técnicos e gestores neutros. Cabe à classe trabalhadora lutar em suas organizações e movimentos para construir uma nação contra aqueles que historicamente moldaram um capitalismo dependente, associado e subordinado ao capital mundial.

Recebido em julho de 2007 e aprovado em agosto de 2007. 


\title{
Notas
}

1. O texto aqui apresentado como subsídio para a Conferência Nacional de Educação Profissional e Tecnológica é, em grande parte, uma síntese de estudos realizados e publicados nos últimos anos. A análise que vinca esta discussão se encontra especialmente em Frigotto (2006), Frigotto, Ciavatta e Ramos (2005 e 2005a) e em Frigotto e Ciavatta (2006).

2. Para uma análise de nossa formação histórica, sobre a qual se assentam as disputas de projetos societários, mormente no século xx, ver Sodré (2004). Sobre capitalismo dependente, ver Fernandes (1975) e Oliveira (2003).

3. Ver, deste autor, especialmente Furtado (1982, 2000).

4. Ver, a esse respeito, Fiori (2002).

5. Ver Oliveira (2005).

6. A curta, mas densa e eloqüente análise de Francisco de Oliveira no artigo "Voto condicional em Luiz Inácio" (Folha de São Paulo, 30 out. 2006) expõe, sem meias palavras, a natureza da esfinge e as conseqüências do não deciframento.

7. Como mostra Saviani (2003), a denominação de Educação Tecnológica em nossa tradição tem assumido equivocadamente o sentido restrito de formação técnico-profissional. Por uma razão pedagógica e política, manteremos neste texto a denominação de Educação Tecnológica ou Politécnica no sentido e contexto que Saviani (2006) propõe.

8. Ver Documento Final do 10 Seminário Nacional sobre Educação Básica de Nível Médio nas áreas de Reforma Agrária. Luziânia, Goiás, 2006 (Relatório final).

9. Ver jornal O Globo (Rio de Janeiro, Caderno País, p. 17, $1^{\circ}$ nov. 2006).

10. Céa (2002) efetiva uma densa análise sobre o PLANFOR, definindo-o não primeiramente como política de formação e qualificação, mas, sobretudo, como política social focalizada e precária dentro da agenda da reforma do Estado e da reestruturação produtiva.

11. Aos que se interessam em aprofundar o debate em relação à gênese, concepção e contradições do Decreto n. 5.154/04, ver: Frigotto, Ciavatta e Ramos (2004, 2005).

12. Para uma melhor contextualização da análise de Anderson, ver Frigotto (2004).

13. Ver, a esse respeito, Frigotto (1983).

\section{Referências bibliográficas}

\begin{abstract}
ALGEBASILE, E. Escola pública e pobreza: os sentidos da expansão escolar na formação da escola pública brasileira. 2004. Tese (Doutorado) - Universidade Federal Fluminense, Niterói.
\end{abstract}

CÂNDIDO, A. A Revolução de 1920 e a cultura. Novos estudos CEBRAP, São Paulo, v. 2, n. 4, p. 44-26, abr. 1984.

CÉA, G.S.S. A qualificação profissional entre fios invisiveis: uma análise crítica do Plano Nacional de Qualificação do Trabalhador. 2003. Tese

Educ. Soc., Campinas, vol. 28, n. 100 - Especial, p. 1129-1152, out. 2007

Disponível em <http://www.cedes.unicamp.br> 
A relação da educação profissional e tecnológica com a universalização da educação básica

(Doutorado em História, Política e Sociedade) - Pontifícia Universidade Católica de São Paulo, São Paulo.

FERNANDES, F. Capitalismo dependente e classes sociais na América Latina. Rio de Janeiro: Zahar, 1975.

FERNANDES, F. A revolução burguesa no Brasil: um ensaio de interpretação sociológica. 3. ed. Rio de Janeiro: Zahar, 1981.

FIORI, J.L. O nome aos bois: Instituto da cidadania. São Paulo: Fundação Perseu Abramo, 2002.

FRIGOTTO, G. Fazendo pelas mãos a cabeça do trabalhador: trabalho como elemento pedagógico na formação profissional. In: CONFERENCIA BRASILEIRA DE EDUCAÇÃO, 2., 1982, Belo Horizonte. Anais... Rio de Janeiro: SENAC/DIPLAn, 1983.

FRIGOTTO, G. Educação e a construção democrática no Brasil: da ditadura civil-militar à ditadura do capital. In: Favero, O.; Semeraro, G. (Org.). Democracia e construção do público no pensamento educacional brasileiro. Petrópolis: Vozes, 2002. p. 53-67.

FRIGOTTO, G. O Brasil e a política econômico-social: entre o medo e a esperança. Observatório Social de América Latina, Buenos Aires, n. 14, p. 95-1004, mayo/ago. 2005.

FRIGOTTO, G.; CIAVATTA, M. (Org.). A formação do cidadão produtivo: a cultura do mercado no ensino médio técnico. Brasília, DF: INEP, 2006.

FRIGOTTO, G.; CIAVATTA, M.; RAMOS, M. A política de educação profissional no governo Lula: um percurso histórico controvertido. Educação \& Sociedade, Campinas, v. 26, n. 92, p. 1087-1113, out. 2005.

FRIGOTTO, G.; CiAVATTA, M.; RAMOS, M. (Org.). Ensino médio integrado: concepção e contradições. São Paulo: Cortez, 2005a.

HOBSBAWM, E. Renascendo das cinzas. In: Blackburn, R. (Org.). Depois da queda: o fracasso do comunismo e o futuro do socialismo. Rio de Janeiro: Paz \& Terra, 1992.

HOBSBAWM, E. O novo século; entrevista a Antônio Polito. São Paulo: Cia das Letras, 2000. 
IANNI, O. Estado e planejamento econômico no Brasil. Rio de Janeiro: Civilização Brasileira, 1966.

LOBO NETO, F.J.S. O discurso sobre tecnologia na "tecnologia" do discurso: discussão e formulação normativa da educação profissional no quadro da lei de diretrizes e bases da educação de 1996. 2006. Tese (Doutorado em Educação) - Universidade Federal Fluminense, Niterói.

MELENCHON, J.L. Por um modelo universal de profissionalização sustentável. Conferência proferida no Fórum Mundial de Educação, Porto Alegre, 2003.

OLIVEIRA, F. Critica da razão dualista: o ornitorrinco. São Paulo: Boitempo, 2003.

OLIVEIRA, F. Há vias abertas para a América Latina? In: Boron, A. (Org.). Nova hegemonia mundial: alternativas de mudanças e movimentos sociais. Buanos Aires: ClACSO, 2005. p. 111-118.

OLIVEIRA, F. Voto condicional em Luiz Inácio. Jornal de Debates. Disponível em:. <http://www.jornaldedebates.ig.com.br/index.aspx>

PAULANI, L. O projeto neoliberal para a sociedade brasileira: sua dinâmica e seus impasses. In: LimA, J. C.F.; Neves, L.M.W. Fundamentos da educação escolar do Brasil contemporâneo. Rio de janeiro: FIOCRUZ, 2006.

POCHMANN, M. O flagelo dos jovens trabalhadores. Folha de S. Paulo, São Paulo, 22 fev. 1998. Caderno Dinheiro, p. 2.

POCHMANN, M. O trabalho sob o fogo cruzado, desemprego e precarização no final do século. São Paulo: Contexto, 1999.

POCHMANN, M. As duas rendas mínimas. Jornal do Brasil, Rio de Janeiro, Outras Opiniōes, p. 922, maio 2004.

PRADO, JR. C. A revolução brasileira. São Paulo: Brasiliense, 1966.

RAMOS, M.N. A pedagogia das competências: autonomia ou adaptação? São Paulo: Cortez, 2001.

SAVIANI, D. Contribuição à elaboração da nova LDB: um início de conversa. $A N D E$, São Paulo, v. 7, n. 13, p. 5-14, 1988. 
A relação da educação profissional e tecnológica com a universalização da educação básica

SAVIANI, D. O choque teórico da politecnia. Trabalho, Educação \& Saúde, Rio de Janeiro, v. 1, n. 1, p. 115-130, 2003.

SAVIANI, D. Trabalho e educação: fundamentos ontológicos e históricos. Trabalho apresentado na 29a Reuniāo Anual da ANPEd, Caxambu, 2006. (mimeo.).

SODRÉ, N.W. Formação histórica do Brasil. Rio de Janeiro: Graphia, 2004.

1152 Educ. Soc., Campinas, vol. 28, n. 100 - Especial, p. 1129-1152, out. 2007 